\title{
Rebuilding the house of health care
}

Richard D. Lamm, LLB, CPA

"If you are going to live in your father's house, you must rebuild it." Johann Wolfgang von Goethe

From the University of Denver, Center for Public Policy and Contemporary Issues, Denver, Colo.

Received for publication May 8, 2007; accepted for publication May 23, 2007.

Address for reprints: Richard L. Lamm, LLB, CPA, University of Denver, Center for Public Policy and Contemporary Issues, 2199 So University Blvd, Denver, CO 80208 (E-mail: rlamm@du.edu).

J Thorac Cardiovasc Surg 2007;134:835-8

0022-5223/ $\$ 32.00$

Copyright () 2007 by The American Association for Thoracic Surgery

doi:10.1016/j.jtcvs.2007.05.042
$\mathrm{I}$ n every age," writes Bronowski in The Ascent of Man, "there is a turning point, a new way of seeing and asserting the coherence of the world."1 The great earthshaking controversies of human history, those between science and religion, church and state, or divine right of kings and democracy, have all been characterized as a "new way of seeing and asserting the coherence of the world." Better advice could not be given for the state of US health care at the beginning of the 21st century: We need "new eyes" and new ways of thinking about our indispensable, but organizationally dysfunctional, health care system.

One of our human dilemmas is to distinguish between the world as it is, rather than as we think it is. Columnist and thinker Walter Lippman warned: "At the core of every moral code, there is a picture of human nature, a map of the universe and a version of history.", Our view of the world and what to expect from it depends greatly on the mental map we have of the world. These mental maps control our most fundamental thinking.

Our mental maps guide us through the bewildering complexities of life. Our mental maps, like real maps, must leave out many concrete features to enable us to make sense of the world around our us and our place in it. ${ }^{3}$ They help us to form our vision of the world. "Visions are indispensable, but dangerous - precisely to the extent that we confuse them with reality itself." ${ }^{\prime 4}$ Visions paint with a broad brush, and often the world changes but our visions do not. Similar to the fast-changing maps of the former Soviet Union over the last 20 years, our painfully acquired mental maps do not always correspond to fast-changing realities. To our great discomfort, the world changes faster than we do.

Let us look with new eyes at how we keep a nation healthy. In health care, the historic role in physicians' mental maps is the role as unrestrained advocate of their patients, and most physicians have a vision of the payer's role as one of passive funder. But painfully, much of the past 20 years has been a process of intruding on that vision and changing the map on the ground as well as in the head. An average of 85 cents out of every health dollar in America is paid by third-party payers (insurance or government), ${ }^{5}$ and the meteoric increase in the costs of health care has spawned a myriad of cost-control measures incompatible with the mental maps in the physicians' heads. Can we not now look back on this dynamic and see that it was inevitable? No technologically advanced health care system can cover all the health care that every physician wants for every patient.

American physicians-indeed, all participants in the US health care systemhave been trained and have practiced their profession during the most massive transfer of resources into a single sector, health care, that any society has seen outside of war. Health care spending has been growing at more than twice the rate 
TABLE 1. Percentage of gross national product

\begin{tabular}{lccc}
\hline & Education & Defense & Health care \\
\hline 1960 & $6 \%$ & $6 \%$ & $6 \%$ \\
2005 & $6 \%$ & $4 \%$ & $16 \%$ \\
Compare the health care spending & equivalents: \\
1965 & 2000 & \\
Health care spending $=$ & Health care spending $=$ \\
education & education, defense, \\
& prisons, farm subsidies, \\
& food stamps, and foreign \\
& aid \\
\hline
\end{tabular}

of inflation for the last 40 years (Table 1). Our practice patterns, medical ethics, medical culture, and public expectations have all been formed during this unprecedented and unsustainable transfer of resources into health care.

We need new maps, new visions, and even new metaphors to reflect the new realities of health care. Learning to live with a sustainable yearly increase in health spending must go dramatically beyond the current dialogue. We cannot reform health care within the current vision. We stand on the threshold of having to make a series of political, public policy, and ethical decisions that will require new maps and new visions. We have developed more things to do to (mostly aging) human bodies than we can pay for. We cannot "grow" our way out of this problem, and no matter what new reformed health care system we may adopt, we will have to set limits on potentially "beneficial" health care. "Limits" is a concept hardly within the American vocabulary. American physicians have been trained to deliver, and American citizens have been acculturated to demand more health care than the nation can afford.

How do we map the new relationship between those who pay for health care and those who receive and deliver health care? Let us "follow the money," and we will see that these health care payers are "partners," not the "intruders" that they have been portrayed to be by popular culture. Yes, the physician is the key actor; no, physicians are not sole actors. Physicians can, in modern medicine at least, only serve their patients by spending other people's money. ${ }^{6}$ Neither government nor insurance companies can give the Hippocratic oath a blank check. However frustrating to physicians, third-party payers cannot blindly pay on demand. Physicians must recognize that third-party payers have their own indispensable functions and moral roles in health delivery.

Government has a moral role in designing and operating its health care system, and its yearly budget is a moral document. Distributing limited funds, as third-party payers do, is a moral role. Modern medicine has thus outgrown its metaphors. We need new metaphors and new visions that better reflect the complicated interrelationships of modern medicine. I suggest that we break down the health function into 4 separate roles and "rebuild the house of health care."
The individual, the physician, the insurer, and the government-each of these carries a separate moral perspective that must be integrated with the other. Think of health care as a 3-story house. The physician is the indispensable first floor of health care, historically and into the indefinite future the key actor in health care. It is a healing perspective, concentrating on the patient, focusing modern skills in a 2000year-old tradition that makes the doctor advocate, fiduciary, healer, and confidant of the patient. This viewpoint lies at the heart of all medicine. The most important role in the lifetime health of an individual is not the physician but the individual's own health habits. Each and every one of us is the chief actor in our present and future health.

We all are, metaphorically, the foundation of both our health and our health care, and each of us has certain moral responsibilities toward our own health. Individual health is increasingly at risk not by external hazards but by bad personal health habits. "Better control of fewer than ten risk factors could prevent between 40 and 70 percent of all premature deaths, one-third of all cases of acute disability and two-thirds of all cases of chronic disability." 7

Modern medicine must require people to have a moral responsibility to keep themselves healthy. People must fully understand that their health habits, not health care, are the key to their health. Yes, this concept will be impossible to fully enforce, but the concept is still useful.

The primary area in which public policy assigns accountability to the individual for his/her health habits is taxation of cigarettes and alcohol. Carrying the concept further is difficult but possible. Great Britain already denies bypass surgery and transplants to patients who refuse to give up smoking, not as punishment but because nonsmokers are better subjects for "effective and efficient surgery." In 2003, the United Kingdom announced, but did not implement, plans to deny obese patients some National Health Service care unless they lose weight. ${ }^{9}$ People cannot have the right to ruin their own health and then expect unlimited coverage from their third-party payer. "There are moral as well as financial limits to society's protection of its members from the risks of poor health," suggests Tristan Engelhardt. ${ }^{10}$

Immediately above the foundation (the individual), we have the first floor of health care, the physicians, who have their moral roles spelled out in medical ethics. But medical ethics do not have adequate moral perspective to allocate third-party resources. Although medical ethics propose to look at "distributive justice," it is essentially (and appropriately) patient-centered and cannot realistically be stretched adequately to serve as the moral foundation to broadly allocate limited resources. Medical ethics offer little practical guidance to third-party payers or governments when faced with a limited pool of money and infinite need. More thinking must go into integrating the role of the first-floor 
physician with the role of payer and the role of government, my metaphoric second and third floors.

The second floor of health care under this metaphor is the insurance function, which consists of the various ways we pool our funds to spread risk. This floor includes private insurance, various managed care organizations, and the government programs of Medicare and Medicaid. The second floor of health care funds all health care except what the patient pays out-of-pocket. The funders on the second floor of health care cannot blindly pay all of the demands of the first-floor physician. These are two separate and distinct moral actors. I would argue that whoever funds health care has a moral duty to wisely spend those funds and must set rules for their use. The second floor not only has the right but also the duty to oversee that these funds are appropriately expended. Haavi Morreim suggests a new concept that she calls "contributive justice," 6 which conceptualizes a moral framework for this second-floor allocation function. Morreim points out that when we pool funds to spread risk in health care, "all members of the group gives up a small benefit, but receive in return a larger benefit, i.e., the ability of the group to optimize the dollars available." ${ }^{\prime 6}$ This level of health care must look at the broad needs of the group and can promulgate polices that maximize the health of the entire group. It is at this level, Morreim argues, that we must realistically recognize the following: "Generous compassion for one is inevitably bought at the expense of the many whose contributions create and who in turn rely on the common resource pool." ${ }^{6}$ Patients cannot expect to pay limited premiums and get unlimited care, but they can expect "contributive justice."

There is a "moral hazard" in buying insurance when we are well and demanding unlimited services when we are sick. "The third party payment system encourages not only marginal medicine; it encourages medicine up to where the benefit approaches zero." ${ }^{11}$ We do have to recognize the insurance company as having some role other than an automatic payer. Insurance companies have to set certain rules and limits to avoid bankruptcy and see that these funds are wisely spent.

The third floor of health care is state and local government, and their moral radius is all the citizens in their jurisdiction. Government must be concerned with the health of all citizens within its jurisdiction. The third-floor function includes the public policy questions of health policy, such as cloning, questions of malpractice, medical research funding, physician training, and the myriad of other public policy functions. It is also the floor that governs the policies that construct the nation's health care system.

A health care system is far more than the sum total of every individual physician in the jurisdiction. More objective assessment is required. We could have every physician practicing the highest ethical medicine and still have an unethical health care system. If I claimed that Colorado had the best "educational system" in the nation, yet I left $16 \%$ of our students without schools, you would laugh me off the stage. We have not spent enough time and talent evaluating this third floor of the house of health care. It is because this third-floor government does play a moral role that causes the claim that America has "the best health care system in the world" to ring hollow.

Assigning different moral roles to health care allows us to also assign responsibilities to each level of health care. This can be particularly useful in the dilemma of how to care for the uninsured. The individual physician cannot be required to treat the uninsured, nor it is fair to burden all the physicians in a given area with treating the uninsured, even if it could be accomplished. Perhaps in a simpler time it was possible, but today when a single patient can cost millions in time and technology, it is no longer practicable or necessary. One can reasonably argue that state and federal legislators "own" the uninsured. As Governor John Kitzhaber observed in conceptualizing his breakthrough Oregon Health Plan, "The legislature is clearly accountable not just for what is funded in the health care budget, but also for what is not funded. Accountability is inescapable."12 (Emphasis added.)

This is a powerful insight. Government has developed a series of programs that now fund more than half of the health care spending in the United States; it is not unreasonable to hold government morally accountable for those who cannot afford health coverage. US health policy funds all those aged more than 65 years with Medicare, including often substantial subsidies to the wealthy elderly. Government can and should be accountable for how it spends the taxpayer's monies. "To govern is to choose," and everything we do in health care prevents us from doing something else. Once government decides to fund health care, certain obligations such as due process and nondiscrimination apply. Governor Kitzhaber merely extends the moral responsibility of government to "what is not funded." I would suggest that not only is the Oregon Health Priorities system ethical, it is unethical not to have such a system of priorities. Whoever distributes limited funds has a moral duty to maximize those funds.

Assigning the government the moral responsibility for health policy within their jurisdiction allows some entity to deal objectively with the broader health of society. Government can and should look at the various public health possibilities that promote health within their jurisdiction, and that can allow them to make those important and necessary tradeoffs in health care funding. When a governor thinks and speaks about someone in a persistent vegetative state, such as Terri Schiavo, his or her moral map should also recognize that his or her jurisdiction is not funding many working poor who have no health insurance. Moral posturing is more difficult in individual cases when the 
full scope of unmet need in one's moral jurisdiction is demonstrated.

Many physicians greeted with skepticism the World Health Organization rating ${ }^{13}$ of the US health care system as 37th among the 191 evaluated. They rightly knew we had the best doctors and the best hospitals in the world. But when we evaluate my metaphorical third floor-federal, state, and local government-we see the justice in this poor rating. A health care system is more than good physicians, hospitals, and technology; it is also making those assets accessible to its citizens. In that, America fails dramatically. Add to the fact that we leave 45 million people without basic health care the equally disturbing fact that our health outcomes are no better than those of many other countries who spend half what we spend, and we must plead "guilty" to our poor ranking.

\section{Conclusions}

More than 50\% of US health care is funded by government, and in government everything we fund prevents us from funding something else. No item in any government budget exists in a vacuum. Yet, "issues in health ethics or medical ethics ... are often considered in abstraction from the social and political context in which they arise." ${ }^{14}$ Such a practice is myopic and unsustainable. We need a larger moral vision for our nation's health care system.

We need a moral foundation for resource allocation in a world where infinite demand has run into finite resources. It is an appreciation of that finiteness, not a narrowness of heart, that directs our efforts. To divide health care considerations into 4 separate but interrelated moral roles can help to clarify that task.

\section{References}

1. Bronowski J. The Ascent of Man. Boston: Little Brown \& Co; 1976.

2. Lippmann W. The Phantom Public. New York: Harcourt Brace; 1925:65.

3. Sowell T. A Conflict of Visions. New York: William Morrow and Company; 1987:13.

4. Sowell T. A Conflict of Visions. New York: William Morrow and Company; 1987:14.

5. Bodenheimer T, Grunbach K. Understanding Health Policy: A Clinical Approach (4th ed.). New York: Lange Medical Books/McGrawHill; 2005.

6. Morreim H. Immoral justice and legal justice in managed care: the ascent of contributive justice. J Law Med Ethics. 1995;23 247-65.

7. Health and Human Services. Available at: http://www.healthierus.gov/ behaviors.html. Accessed January 2007.

8. Daily Mail. Available at: http://www.dailymail.co.uk/pages/live/ articles/news/news.html?in_article_id $=459574 \&$ in_page_id $=1770$. Accessed December 2006.

9. Blank RH, Burau V. Comparative Health Policy. New York: Palgrave Macmillan; 2004:116.

10. Engelhardt HT. The Foundation of Bioethics. Oxford: Oxford University Press; 1996.

11. Russell LB. Is Prevention Better Than Cure? Washington, DC: Brookings Institution; 1986.

12. Kitzhaber J. The Oregon Solution. Speech to the Conference on Health Care, August 9, 1991, Portland, Oregon, p. 9.

13. World Health Organization. Available at: http://www.who.int/whr/ 2000http://www.who.int/whr/2000 _wbhttp://www. Accessed December 2006.

14. Charlesworth M. Bioethics in a Liberal Society. Cambridge: Cambridge University Press; 1993:1. 